\title{
IT RELIABILITY FOR ENSURING PERFORMANCE OF IT USED IN ORGANIZATIONS OPERATING UNDER COVID-19 EPIDEMIC CRISIS
}

\section{Tworek, K.}

Katarzyna Tworek / Wrocław University of Science and Technology, Faculty of Computer Science and Management, Department of Management Systems and Organizational Development, wyb. Wyspianskiego 27, 50-370 Wroclaw, Poland.Email: katarzyna.tworek@pwr.edu.pl.

\begin{abstract}
The article concerns the analysis of elements building the reliability of IT solutions used in the organizations (system reliability, usage reliability, information reliability and support service reliability) and their influence on IT performance in conditions of the crisis, which calls for social-distancing and forces employees to work remotely, putting IT performance at the centre of attention for organizations seeking ways to survive the crisis. The article aims at verifying the IT Reliability Model under such conditions and identifies which elements building the reliability of IT solutions may contribute to ensuring IT performance. The empirical study is performed among 115 organizations operating in Italy during the COVID-19 epidemic crisis in March 2020 (during the lockdown and peak of the epidemic). The results are compared with a previous study performed among 349 organizations from Poland and 288 organizations operating in Switzerland operating under normal conditions in January 2019. The obtained results confirmed that there are major differences in the strength and significance of the influence of four elements building IT reliability on IT performance among employees from organizations working under normal conditions and conditions of epidemical crisis. The usage reliability and support service reliability were proven to become key factors influencing IT performance under such critical conditions.

Implications for Central European audience: Central Europe was hit by the COVID-19 pandemic, and most of the organizations experienced problems with their functioning due to the need to establish new ways of working in a world of social distancing rules. Information technology became an especially important factor allowing them to remain continuity. Therefore, the analysis of factors influencing its performance during the crisis may help contemporary organizations in Central Europe to overcome the crisis caused by the sudden need to relay, more than ever, on information technology.
\end{abstract}

Keywords: information technology; management; IT reliability; IT performance; COVID-19; epidemic crisis

JEL Classification: M15, M10

\section{Introduction}

The contemporary world is increasingly dependent on the support of information technologies (IT), which may be considered as a source of both strength and weakness. The normal conditions of functioning allow those organizations to obtain measurable benefits from IT 
support and facilitate their decisions to use them on a daily basis. However, what is an additional benefit under normal conditions, may be the sole factor determining the ability to survive under critical conditions of crisis (Jefferson, 2006), which forces organizations to introduce forced remote work and rely on their IT solutions to ensure business continuity. What was considered to some extent as the theoretical problem and analyzed in the context of maintaining business continuity with the support of IT, now became a real-life issue for contemporary organizations struggling to maintain operations during COVID-19 epidemic crisis, which called for social-distancing and forced employees around the world to remote work (Bénassy-Quéré et al., 2020). The occurrence of such a situation calls for immediate research to indicate mechanisms, which may be used by organizations to survive the crisis and facilitate IT performance in conditions in which IT solutions are especially needed. It seems that various features of IT solutions used in organizations may contribute to their proper performance in such critical conditions. However, it would be wrong to assume that it is enough to use the models indicating factors shaping IT performance, which are verified under normal conditions. It seems to be an important and valid field of study, especially because of the unprecedented scale of the crisis and the need for remote work, which puts IT performance at the centre of attention and forces organizations to obtain it regardless of the quality and reliability of IT solutions they have at their disposal, as they need to use what they have anyway. Moreover, the use of various IT solutions in the context of crisis management is present in the literature (concerning specific information systems, e.g. dynamic emergency response management information systems by Turoff et al. (2004), GeoCollaborative by MacEachren et al. (2006) or concerning crisis management systems overall, e.g. Pan et al. (2012) or Reuter et al. (2012)), but there is a clear gap concerning the lack of analysis on shaping the performance of all typical IT solutions, which are not dedicated for crisis management, but rather available for every-day use and must become a key resource of the organizations during such critical conditions.

The article aims to verify the IT Reliability Model under the critical conditions of epidemic, which calls for a need to work remotely from home (in unprecedented scale), forcing employees to use IT solutions to facilitate the possibility to make the work done and identify which elements of IT Reliability Model may contribute for ensuring IT performance. The need for such verification is arising from a clear research gap - lack of empirical studies allowing for the analysis of factors influencing the performance of IT solutions used in organizations in the situation in which employees are forced to use given IT solutions and "do their best" to get their work done due to lack of other possibilities for it. In order to achieve the aim of the article, the empirical research will be conducted among organizations operating in critical conditions of the COVID-19 epidemic in Italy (in March 2020), and the results will be compared with previously obtained from the sample of organizations operating in normal conditions in Poland and USA (in January 2019).

\section{IT Reliability for ensuring IT performance}

\subsection{IT reliability model}

The reliability of IT in the organization is considered as a measure of IT solutions stability over a variety of conditions (Zahedi, 1987) and is understood as "measurable property of IT solutions, useful for their control and management, identifying their quality level and pointing out potential problems" (Zahedi, 1987, p. 188). The IT Reliability Model has been developed 
by Tworek (2018a, 2018b) and builds by factors connected with three well-known IT analysis frameworks. The first one is DeLone and McLean success model (DeLone \& McLean, 2003), the second one is Lyytinen (1987) types of IS failure, and lastly, Technology Acceptance Model (TAM) model (Davis, 1989). Based on them, four elements of the IT Reliability Model were identified: system reliability, usage reliability, information reliability and support services reliability. The proposed model was verified using four different samples and various statistical tools: ranking analysis (Tworek, 2018b), correlation analysis (Tworek, 2018a; Tworek, 2019), regression analysis (Tworek, 2018b), regression analysis with moderators (Bieńkowska et al., 2020; Tworek, 2019) and multidimensional correspondence analysis (Tworek, 2020).

The system reliability is directly linked to system quality and is by far the most important outcome variable conditioning IT performance (DeLone \& McLean, 2003), allowing to measure the desired characteristics of each information system within the IT solution (DeLone \& McLean, 2016; Tworek, 2019). DeLone and McLean (2003) indicated that the most relevant characteristics of system reliability are connected to resource and investment utilization and should be interpreted in the light of outputs of information systems. According to Tworek (2019), the following items should concern system reliability: Replaceability (the ease of replacement of system's elements with new ones), Security (the system ability to protect itself from unauthorized access), Hardware stability (the frequency of break downs of hardware), Hardware performance (the ability to efficiently perform computing operations), Availability (the ease of access to the system and rate of its unavailability for users), Saliency (the ease to understand the software structure), Compatibility (the ability to move information between different parts of the system) and Adaptability (the ability to adapt to changing requirements of users). Based on the IT Reliability Model verification and various considerations (Tworek, 2019), it can be assumed that system reliability is understood as the ability to operate without disruptions maintaining security, stability and availability.

The usage reliability is, in turn, connected directly to the usability (and therefore, initially included by Tworek (2019) as a part of system reliability). Usability is understood as "the extent to which a product can be used by specified users" (ISO 9241-1(1998)) and can be broadly understood as the quality of use, which is highly dependent on user perception and can be a source of satisfaction and high job performance (Bieńkowska et al., 2020). It is highly underlined as an extremely important attribute of IT solutions quality and is increasingly underlined as equal to traditional attributes such as security or performance (Yeh \& Lin, 2015). However, satisfaction with the use of IT is related to the internal belief (perception of a user) that the IT meets the requirements and is connecting usability to acceptance of IT. There are two basic factors determining the acceptance of IT: perceived usefulness, described as "the degree to which an individual believes that using a particular system would enhance his or her job performance" (Moore \& Benbasat, 1991, p. 197), connected to the IT performance and perceived ease of use, described as "the degree in which an individual believes that using a particular system would be free of physical and mental effort" (Moore \& Benbasat, 1991, p. 197), connected to the freedom from difficulty or effort, translating sometimes into the satisfaction. Based on such considerations, according to Tworek (2019), following items are building usage reliability: Acceptance (the willingness to use the system), Efficiency (the level of energy needed from the user to put into the system to produce the desired result), Memorability (the level of effort needed from an experienced user to remember how to act in the system), Error proneness (the frequency of confusion within the 
system causing user error), Learnability (the level of effort needed from a new user to understand how to act in the system), Responsiveness (the period of time needed for system reaction to users' action). Based on the IT Reliability Model verification and considerations of Tworek (2019), it can be assumed that usage reliability is understood as the employees' ability to perform tasks using IT, which is efficient and accepted by them.

Information reliability is recognized as a phenomenon closely related to information quality and credibility - both especially important for the management of information within the organization, including those from IT solutions used in the organization (Hilligoss \& Rieh, 2008; Tomaél, 2000). Representational faithfulness is considered as the most important characteristics of information reliability. It is understood as "the correspondence or agreement between a measure or description and the phenomenon it purports to represent" (FASB, 1978, p. 1163). Verifiability (important in case of information reliability, however less important in case of reliability of the information included in IT), understood as "the ability through consensus among measurers to ensure that information represents what it purports to represent or that the chosen method of measurement has been used without error or bias" (FASB, 1978, p. 1159), should also be considered here. Such an understanding of this concept is consistent with empirical research performed by Tworek (2019), who formulated the notion of reliability of the information included in IT used in the organization, indicating the following aspects: Accessibility (the ability to access information included in IT), Searchability (the ability and efficiency of searching through the information included in IT), Accuracy (the quality and credibility of information included in IT), Relevance (the ability to avoid irrelevant and overlapping information included in IT), Archivability (the ease of archive the information included in IT), Portability (the ability to move information included in IT between different system environments) and Movability (the ability to move information included in IT between disk spaces). Based on the IT Reliability Model verification and Tworek's (2019) considerations, it can be assumed that IT information reliability is understood as the ability to easily access relevant and accurate information gathered, generated, stored and processed by IT.

The support services reliability is connected to the organizations' ability to support their employees in using IT solutions. Even though the authors recognize IT control as a key challenge for contemporary organizations (Cram et al., 2016; Gregory et al., 2013), the coverage concerning support services exercising that control and ensuring the reliability of those IT is very little. The initial model of DeLone and McLean (2003) was composed of system and usage quality. However, the research, which followed it, revealed that both of those are highly dependent of service quality, which can be recognized as "the overall support delivered by the service provider, applies regardless of whether this support is delivered by the IS department, a new organizational unit, or outsourced to an Internet service provider (ISP)" (DeLone \& McLean, 2003, p. 25). Based on the literature review, according to Tworek (2019), several items are building the support service reliability: Assurance (the level of assurance that supports service will perform tasks properly), Empathy (the ability to understand the user's problem), quality (the ability to solve user's problem), Fail rate (the frequency of support services need, caused by system fails), Availability (the ease of reaching support services and getting needed service), Responsiveness (the timeframe of reaching support services and getting needed service. Based on the IT Reliability Model verification and various considerations (Tworek, 2019), it can be assumed that support service reliability 
is understood as the ability to establish support services for IT, which will be available and highly responsive for employees.

\subsection{IT performance}

The performance of IT has no commonly accepted definition since most of the authors in the contemporary literature state that IT performance is shown directly in organizational performance (e.g. Devaraj \& Kohli, 2003). However, there are some aspects of IT performance, which were most frequently cited in the literature from the previous century: IT contribution to organizational financial performance, IT operational efficiency and adequacy to system development practices, user and managers attitude, personnel competences and development and IT planning (Bieńkowska et al., 2020; Saunders \& Jones, 1992). However, it needs to be underlined that nowadays, IT performance is concerning not only the ability of IT to operate properly on a daily basis but also to ensure proper operation through critical conditions, which are limiting the organization ability to maintain the typical line of work and more and more often rely on remote work, stretching the initial functionalities of IT solutions, which were not necessarily designed to support all aspects of such way of operations. That is the main reason why four crucial aspects of IT performance should be underlined (identified by Bieńkowska, Tworek \& Zabłocka-Kluczka (2020) in their Organizational Reliability Model):

1) IT solutions proper functioning (within the limits of Service Level Agreement (SLA, which is the standard implemented to provide guarantees on the quality of services connected to the use of IT solutions to end-users (Ludwig et al., 2003)). SLA "defines the delivery ability of a provider, the performance target of consumers' requirement, the scope of guaranteed availability, and the measurement and reporting mechanisms" (Wu \& Buyya, 2012, p. 5) and in general describes boundaries and expectations for what is called a proper operation within the organization - those expectations should be met especially in critical conditions, in which organization is especially dependent of IT solutions. Therefore, it can be said that there are two basic roles of SLA: reducing the risk of prolonged unavailability periods and offering protection against possible losses (Mastroeni et al., 2019) — both of them may be used as a starting point for creating and maintaining plans for ensuring IT operations continuity through critical conditions.

2) Support of IT functionalities for the tasks performed by employees. Next to the SLA, the alignment between IT solutions support, given by their functionalities and employees' requirements, is the main factor shaping IT performance (Luftman et al., 2017; Tworek, 2019), since it allows the organization to gain benefit from IT operating within the given SLA. That is important, especially during critical conditions, in which IT solutions must also be aligned with new employees' requirements, which are arising from the critical situation itself and their need for performing their work in these changed conditions. Alignment between IT functionalities and employees' requirements is based on coordinating activities across IT and non-IT domains within the organization, which allows you to obtain IT designed to support tasks performed by the employees in ways, which allow for their most efficient fulfilment, which translated into IT performance.

3) Correctness of the information received from IT solutions. It should be underlined that the quality of information gathered, stored, processed and distributed by IT 
solutions is depending on the ability of IT solutions to function within the SLA and their alignment with employees' needs. Since the information (Martin, 2017) and knowledge (Al-Emran et al., 2018) are one of the most important assets of every organization, their correctness seems to be a key in establishing IT performance both in normal and critical conditions or even especially in critical conditions in which IT solutions may be the only source of that information.

4) Employees willing performance of tasks with the support of IT, which was designed for them. It is a well-known fact that the acceptance of IT solutions, which are designed to support the tasks implemented by employees, is crucial for efficient use of IT functionalities, which are well-aligned to the needs of employees and functioning within the given SLA. When Davis (1989) proposed the Technology Acceptance Model, he underlined that the efficient use of IT is conditioned by employees' behavioural intention to use it. Without such intention and willingness to use IT solutions available in the organization, employees will always fulfil tasks in a way, which is perceived by them as easier and not use the support of IT, even if it is available for them (Van der Heijden, 2004; Tworek, 2019). However, there are some critical conditions in which this willingness is not considered - employees are forced to use IT solutions, e.g. for implementing work remotely in critical conditions of epidemic threat. In such cases, employees are forced to use IT solutions to implement tasks and have to do "their best" without the real behavioural intention to do so. By definition, IT performance is much worse in such conditions, and there is a need to find ways to enhance it, allowing organizations to operate in critical conditions as well as possible.

\subsection{IT Reliability shaping IT performance in critical conditions}

The notions of IT reliability and IT performance are well-embedded in contemporary literature but connected mainly to the normal functioning of the organization. However, it seems that with the growing digitalization of the world and the rising dependence of contemporary organizations on their IT support, there is a need for considering the role of IT reliability in shaping IT performance in critical conditions as well. According to Seeger et al. (2003), critical conditions (understood as the conditions of crisis) occur when three assumptions are met: situation threatens high priority organization goals, the situation presents restrictions concerning the amount of time for decisions, and the situation is unexpected or unanticipated by the organization. One of the specific types of a crisis situation is a lockdown, and it concerns critical conditions forcing organizations to shift their way of operations to facilitate business continuity during the lack of employees' ability to leave their place of residence (e.g. during the epidemic crisis) (Powley, 2009). Such conditions occurred during the COVID-19 epidemic crisis in 2020, forcing the world to change the way of working in order to facilitate the need for social-distancing, which seems to be the only way to fight the coronavirus SARSCoV-2. A growing number of researchers is underlining the need for searching for any mechanisms, which will allow organizations to start operating more efficiently under such conditions (Bénassy-Quéré et al., 2020). The conditions of lockdown are a type of crisis situation which is especially demanding in case of IT support to maintain organizations continuity. It seems that when the only way of working is remote work (Thompson, 2019), the need for IT solutions to perform properly is higher than usual, and IT performance becomes one of the important factors influencing the performance of an organization as a whole 
(Watkins, 2020). Remote work, even when performed willingly by employees, has limitations, and even though it was initially treated as the golden solution limiting the organizational costs, nowadays it is not considered as the best choice anymore (Simons, 2017). It seems that in the critical conditions when employees are not working remotely by choice, but they are forces to do so by the situation, negative aspects of such a way of working are much more visible. Hence, the ability to ensure IT performance through such critical conditions to facilitate the possibility to perform tasks by employees', who are unwillingly using the IT solutions to perform tasks in a way in which they do not usually do, is the most crucial for any organization, which wants to survive such crisis.

The main reason why the elements building IT reliability should substantially influence IT performance during critical conditions is lying in the fact that they are profoundly connected with the availability of IT solutions. As stated by Tworek (2019), reliability is closely connected with availability and such feature is underlined in case of system reliability and support services reliability, stating that their availability is a key prerequisite without which it is impossible to state that IT used in an organization is reliable. Such seemingly simple conclusions seem to gain importance in the critical situation, in which the availability of IT solutions and their support services is not that apparent and accumulating efforts in order to achieve such availability in critical conditions is one of the most important tasks during the crisis.

However, under critical conditions, in which employees are forced to use given IT solutions and the performance of their job is directly dependent of that use, it seems possible that the assumption of most researchers (e. g. DeLone \& McLean, 2003), stating that system reliability and all its features are the most important determinant of IT performance, will no longer be true. It seems that in a situation, which employees are forced to work with what they have, the IT performance will be more reliant on other factors, as there will be no possibility for a quick change in any system within a given IT solution, and reliable or not, it would need to be used the way it is. It seems that in such critical conditions, the reliability of usage may become an important factor determining the performance of IT. That is mainly because employees who are forced to work with given IT solutions will be able to work efficiently when they are accepting the solution, perceive it as easy to use and identify its usability as high. Obtaining such a perception among employees seems possible under critical conditions when they will see that the IT solutions available within the organization are making it possible for them to perform their work (at least to some extent) in such unfavourable conditions. Therefore, it seems that the manager's efforts should be directed at shaping a positive attitude of employees towards the IT solutions they are forced to use. It seems consistent with the views of Venkatesh et al. (2003), who offered Unified Theory of Acceptance and Use of Technology, introducing "facilitating conditions" as one of the elements of the model. It seems that conditions of crisis, which forces employees to work remotely in order to keep their job and maintain continuity of the organization, in which they work, may be a perfect example of such facilitating conditions, showing that they are indeed translating into the actual use of given IT solutions. Hence, based on those considerations, the following hypothesis may be formulated:

H: Usage reliability is the element of IT Reliability significantly influencing IT performance under critical conditions. 


\section{Methodology}

In order to verify the proposed hypothesis, the empirical research based on a survey (gathered using CAWI method) was conducted in two phases:

Phase 1: Organizations from European Union countries (Poland and Switzerland) operating in normal conditions (sample obtained in January 2019).

Phase 2: Organizations from European Union countries (Italy) operating under critical conditions of COVID-19 epidemic (sample obtained in the period of 18-22nd of March 2020, when Italy was experiencing full lockdown, number of COVID-19 cases was exceeding 40,000 and number of deaths from COVID-19 was exceeding 4,000, all organizations were forced to introduce remote work if it was possible).

The characteristics of the obtained sample are presented in Table 1 and 2, showing that the sample from Phase 1 is covering 349 organizations from Poland and 288 organizations operating in Switzerland, and the sample from Phase 2 used for comparison is covering 115 organizations from Italy. Both surveys have been filled in by managers from surveyed organizations. Several control variables were introduced to confirm the proper diversity of the sample (size and time of operations of the organization, industry type) and to confirm that management support IT solutions were implemented in those organizations (respondents were aware that the questions concerned those solutions). Additionally, in order to make sure that the organizations from the sample obtained for Phase 2 are meeting the assumption of operating under critical conditions, additional questions concerning the negative influence of the COVID-19 epidemic on their operations were included in the research. All organizations declared enormous influence on the critical conditions of the epidemic on all areas of an organization's operations and the need for the introduction of remote work in order to ensure the continuity of operations.

Table 1 | Size and time of operation of organizations included in the sample from Phase 1

\begin{tabular}{lccccc}
\hline & \multicolumn{3}{c}{ Time of operations } & Total \\
\hline Organization size & $\begin{array}{c}\text { Less than } \\
\text { a year }\end{array}$ & $\begin{array}{c}1 \text { to } 5 \\
\text { years }\end{array}$ & $\begin{array}{c}5 \text { to } 10 \\
\text { years }\end{array}$ & $\begin{array}{c}\text { More than } \\
10 \text { years }\end{array}$ \\
\hline Micro (below 10 people) & 24 & 58 & 40 & 3 & 125 \\
Small (11-50 people) & 30 & 68 & 66 & 6 & 170 \\
Medium (51-250 people) & 15 & 86 & 89 & 13 & 203 \\
Large (above 250 people) & 12 & 56 & 63 & 8 & 139 \\
Total & 81 & 268 & 258 & 30 & 637 \\
\hline
\end{tabular}

Source: author 
Table 2 | Size and time of operation of organizations included in the sample from Phase 2

\begin{tabular}{|c|c|c|c|c|c|}
\hline \multirow[b]{2}{*}{ Organization size } & \multicolumn{4}{|c|}{ Time of operations } & \multirow[t]{2}{*}{ Total } \\
\hline & $\begin{array}{l}\text { Less than } \\
\text { a year }\end{array}$ & $\begin{array}{l}1 \text { to } 5 \\
\text { years }\end{array}$ & $\begin{array}{l}5 \text { to } 10 \\
\text { years }\end{array}$ & $\begin{array}{c}\text { More than } \\
10 \text { years }\end{array}$ & \\
\hline Micro (below 10 people) & 6 & 5 & 4 & 4 & 19 \\
\hline Small (11-50 people) & 4 & 15 & 7 & 1 & 27 \\
\hline Medium (51-250 people) & 1 & 8 & 20 & 7 & 36 \\
\hline Large (above 250 people) & 2 & 4 & 14 & 13 & 33 \\
\hline Total & 13 & 32 & 45 & 25 & 115 \\
\hline
\end{tabular}

Source: author

\subsection{Variable overview}

The performed research was based on five variables (their characteristics for both samples are given in table 3):

System reliability (first element of IT reliability), which was measured based on item: "IS, which are used in the company to perform tasks are reliable (high availability, stability and security)." The scale was based on a 5-point Likert scale (from I strongly disagree to I strongly agree with a middle point: I have no opinion).

Usage reliability (second element of IT reliability), which was measured based on item: "Usability of those IS is high (efficient, accepted and easy to use)." The scale was based on a 5-point Likert scale (from I strongly disagree to I strongly agree with a middle point: I have no opinion).

Information reliability (third element of IT reliability) which was measured based on item: "Information included in those IS are reliable (accurate, relevant and easily accessible)." The scale was based on a 5-point Likert scale (from I strongly disagree to I strongly agree with a middle point: I have no opinion).

Support services reliability (fourth element of IT reliability), which was measured based on item: "Support services for those IS are reliable (available and responsive)." The scale was based on a 5-point Likert scale (from I strongly disagree to I strongly agree with a middle point: I have no opinion).

IT performance, which was measured based on 4 items covering four areas of IT operations, which are crucial for building its proper support for organization explained in the second section. The scale was based on a 5-point Likert scale (from I strongly disagree to I strongly agree with a middle point: I have no opinion). 
Table 3 | Characteristics of variables

Normal conditions (2019) Critical conditions (2020)

\begin{tabular}{lcccccccc}
\hline No & Variable & $\begin{array}{c}\text { No. of } \\
\text { scales }\end{array}$ & $\begin{array}{c}\text { Alpha- } \\
\text { Cronbach }\end{array}$ & M & SD & $\begin{array}{c}\text { Alpha- } \\
\text { Cronbach }\end{array}$ & M & SD \\
\hline 1 & system reliability & 5 & - & 3.45 & 1.34 & - & 3.44 & 1.00 \\
2 & $\begin{array}{c}\text { usage reliability } \\
\text { information }\end{array}$ & 6 & - & 3.51 & 1.26 & - & 3.44 & 0.97 \\
3 & $\begin{array}{c}\text { reliability } \\
\text { support service }\end{array}$ & 4 & - & 3.54 & 1.23 & - & 3.65 & 0.95 \\
4 & $\begin{array}{c}\text { reliability } \\
\text { IT performance }\end{array}$ & 4 & 0.915 & 3.60 & 1.07 & 0.909 & 3.44 & 0.73 \\
\hline
\end{tabular}

Source: author

\section{Research results}

In order to verify the influence of each IT Reliability Model elements on IT performance, a regression analysis was performed. Two regression models were built. The linear regression analysis was used, and all the assumptions allowing to use of linear regression with data obtained from Likert-based questions were met. The first one was built based on the sample obtained from Phase 1, showing the relations occurring in normal conditions - it was statistically significant and well- fitted $\left(F(4,107)=52,214, p<0,001 ; R^{2}=0,657\right)$. The second one was built based on the sample obtained from Phase 2, showing the relations occurring in critical conditions - it was also statistically significant and well- fitted $(F(4,623)=363,371, p$ $\left.<0,001 ; R^{2}=0,698\right)$. It is worth noting that both models express a similar level of explaining the variability of the dependent variable - around $65 \%$, which is very high for management sciences. The comparison of the influence strength of each independent variable influence on IT performance from both obtained models is presented in Table 4.

Table 4 | Comparison of the regression models for normal and critical conditions

$$
\text { Normal conditions (2019) Critical conditions (2020) }
$$

\begin{tabular}{lcccccc}
\hline $\begin{array}{l}\text { Independent } \\
\text { variables }\end{array}$ & Beta & $\begin{array}{c}\text { Standard } \\
\text { error }\end{array}$ & P value & Beta & $\begin{array}{c}\text { Standard } \\
\text { error }\end{array}$ & P value \\
\hline (constant) & 0.793 & 0.079 & 0.000 & 0.920 & 0.184 & 0.000 \\
\hline $\begin{array}{l}\text { system } \\
\text { reliability }\end{array}$ & 0.181 & 0.031 & 0.000 & 0.068 & 0.060 & 0.265 \\
\hline $\begin{array}{l}\text { usage } \\
\text { reliability }\end{array}$ & 0.204 & 0.032 & 0.000 & 0.246 & 0.064 & 0.000 \\
\hline $\begin{array}{l}\text { information } \\
\text { reliability }\end{array}$ & 0.165 & 0.033 & 0.000 & 0.039 & 0.066 & 0.561 \\
\hline $\begin{array}{l}\text { support } \\
\text { service } \\
\text { reliability }\end{array}$ & 0.245 & 0.031 & 0.000 & 0.370 & 0.061 & 0.000 \\
\hline
\end{tabular}

Source: author 
The obtained results show that there are significant differences between the two obtained models. The model obtained for normal conditions confirms that all elements of IT Reliability Model have a statistically significant influence on IT performance. However, the model obtained for critical conditions show that only usage reliability and support service reliability are statistically significantly influencing the IT performance. Hence, the obtained results allow us to accept the proposed hypothesis, stating that Usage reliability is the element of IT Reliability significantly influencing IT performance under critical conditions.

\section{Discussion}

Under critical conditions, in which employees are forced to work from home, and IT solutions become the necessity for them in order to get any work done, the role of IT reliability in shaping IT performance looks entirely different. The obtained results show that only two out of four elements of IT reliability are statistically significant elements of the obtained regression model built for IT performance. System reliability and information reliability are proven not to be significant elements of the obtained model. It confirms that in critical conditions, when employees are forced to use IT solutions, the reliability of the system itself and information contained in it are not that important - the solution must be used anyway, no matter what is its quality. Therefore, the perceived reliability of system and information does not influence the performance of IT solutions to a significant extent. In such critical conditions, usage reliability and support service reliability are becoming key for perceiving IT solutions as reliable and determining the performance of IT. The obtained results show that even in cases in which the system itself and information given by it are not reliable, in the situation of forced use of such solution, their usage and support services reliability are a key for ensuring proper operations and performance of IT. Hence, the IT solution does not have to perfect - in critical conditions, even imperfect solutions may bring true benefits for organizations, which ensure reliable usage of those solutions and proper support for this use. Moreover, the obtained results show that available and responsive support services are even more important $(B=$ 0,370 for support services reliability) as efficient, accepted and easy to use IT solutions ( $B=$ 0,246 for usage reliability), because even when the usability is not that great, support services make it manageable for the employees to get the work done. Moreover, those results allow to further explain the views of Venkatesh et al. (2003), who introduced "facilitating conditions" as one of the elements influencing acceptance and use of any technology (including IT solutions). The results allow us to prove what was assumed before, that conditions of crisis, which force employees to work remotely in order to keep their job and maintain continuity of organization are indeed a perfect example of such facilitating conditions, causing usage reliability to gain importance in obtaining IT performance and enabling support service reliability to be a factor allowing those employees to use the given IT solutions and gain benefit from that use. Hence, it seems that support service reliability is acting as an enabler allowing for acceptance and use of IT solutions in the facilitating conditions of crisis.

\section{Conclusions}

The performed empirical research allowed to verify the IT Reliability Model (Tworek, 2019) and identify IT reliability role in shaping IT performance under the situation of epidemical crisis, which called for a need to work remotely from home (in unprecedented scale) — such working conditions forced them to use IT solutions to facilitate the possibility to make the work done. Such conditions allowed to verify the IT Reliability Model among employees, who were 
forced to fully depend on given IT solutions. The obtained results confirmed that there are major differences in the strength and significance of the influence of four elements building IT reliability on IT performance among employees from organizations working under normal conditions and under conditions of epidemical crisis, causing them to work remotely and depend on IT solutions to make their work done. It was proven that under such critical conditions, only usage reliability and support services reliability are the factors determining the performance of IT. Hence, the obtained results allow to not only accept the proposed hypothesis stating that usage reliability is the element of IT Reliability Model most significantly influencing IT performance under critical conditions, but also underlines that support services reliability play an important role in ensuring this usage reliability. It allowed to fulfil the aim of the article and fill in the identified research gap - offering the analysis on shaping the performance of typical IT solutions, which are not dedicated to crisis management, but rather available for every-day use and suddenly become a key resource of the organizations operating during critical conditions.

The obtained results have a significant value for both theory development and practice. From the theory developed in the field of reliability of IT used in organizations, the research shows that the IT Reliability Model looks different under normal conditions and critical conditions of epidemic crisis. It seems that a key factor showing the most important difference among those two situations from the point of view of IT performance is connected to employees' willingness to use IT. In the latter case (critical conditions), such a willingness is not taken into account, as employees are forced to use IT, and it causes a significant shift in the IT Reliability Model (from the point of view of ensuring IT performance), underlining the significance of usage reliability and support service reliability, mitigating the role of system reliability itself and reliability of the information contained in it (which are both proven to be significant for IT performance under normal conditions). From the point of view of practice, the results should be treated as a beacon for managers - even when IT solutions used in the organization are not perfect (the system itself is not perceived as reliable, and information processed within it are also not perceived in this way), ensuring usage reliability (also through organizing reliable support services) is a key for obtaining IT performance under critical conditions. Since IT performance is a prerequisite for maintaining operations of such organizations during crisis conditions, those findings may be an important drop in a bucket showing managers what they may do to ensure organizational continuity.

The performed research has some limitations. The obtained sample of 115 organizations working under critical conditions is, by far, not a representative sample. However, since the COVID-19 epidemic crisis changed how Europe works and Italy as a centre of the epidemic became the region, which is affected by those changes to the greatest extent, it seems that obtained results show some trends allowing to pinpoint factors crucial for obtaining IT performance. The results clearly need further research and in-depth analysis but might be useful now for proposing some actions mitigating the crisis.

\section{References}

Al-Emran, M., Mezhuyev, V., Kamaludin, A., \& Shaalan, K. (2018). The impact of knowledge management processes on information systems: A systematic review. International Journal of Information Management, 43, 173-187. DOI 10.1016/j.jijinfomgt.2018.08.001

Bénassy-Quéré, A., Marimon, R., Pisani-Ferry, J., Reichlin, L., Schoenmaker, D., \& Weder, B. (2020). 13 COVID-19: Europe needs a catastrophe relief plan. In R. Baldwin \& B. Weder di Mauro (Eds.). 
Mitigating the COVID economic crisis: Act fast and do whatever it takes (pp. 121-128). London, UK: CEPR Press.

Bieńkowska, A., Tworek K., \& Zabłocka-Klucza, A. (2020). Organizational reliability: Human resources, information technology and management [in press]. London, UK: Routledge.

Cram, W. A., Brohman, K., \& Gallupe, R.B. (2016). Information systems control: A review and framework for emerging information systems processes. Journal of the Association for Information Systems, 17(4), 2. DOI 10.17705/1jais.00427

Davis, F. D. (1989). Perceived usefulness, perceived ease of use and user acceptance of information technology. MIS Quarterly, 13(3), 319-340. DOI 10.2307/249008

DeLone, W. H., \& McLean, E.R. (2003). The DeLone and McLean model of information systems success: A ten-year update. Journal of management information systems, 19(4), 9-30. DOI 10.1080/07421222.2003.11045748

DeLone, W.H., \& McLean, E.R. (2016). Information systems success measurement. Foundations and Trends ${ }^{\circledR}$ in Information Systems, 2(1), 1-116. DOI 10.1561/2900000005

Devaraj, S., \& Kohli, R. (2003). Performance impacts of information technology: Is actual usage the missing link? Management science, 49(3), 273-289. DOI 10.1287/mnsc.49.3.273.12736

Financial Accounting Standards Board (FASB) (1978). Objectives of financial reporting by business enterprises. Statement of Financial Accounting Concepts No. 1 [online]. Retrieved from https://www.fasb.org/resources/ccurl/816/894/aop_CON1.pdf

Gregory, R. W., Beck, R., \& Keil, M. (2013). Control balancing in information systems development offshoring projects. MIS Quarterly, 37(4), 1211-1232. DOI 10.25300/misq/2013/37.4.10

Hilligoss, B., \& Rieh, S. Y. (2008). Developing a unifying framework of credibility assessment: Construct, heuristics, and interaction in context. Information Processing \& Management, 44(4), 1467-1484. DOI 10.1016/j.jpm.2007.10.001

Jefferson, T. L. (2006). Evaluating the role of information technology in crisis and emergency management. Vine, 36(3), 261-264. DOI 10.1108/03055720610703542

Ludwig, H., Keller, A., Dan, A., King, R., \& Franck, R. (2003). A service level agreement language for dynamic electronic services. Electronic Commerce Research, 3(1-2), 43-59. DOI 10.1109/wecwis.2002.1021238

Luftman, J., Lyytinen, K., \& Zvi, T. B. (2017). Enhancing the measurement of information technology (IT) business alignment and its influence on organization performance. Journal of Information Technology, 32(1), 26-46. DOI 10.1057/jit.2015.23

Lyytinen, K. (1987). Different perspectives on information systems: problems and solutions. ACM Computing Surveys (CSUR), 19(1), 5-46.

MacEachren, A. M., Cai, G., McNeese, M., Sharma, R., \& Fuhrmann, S. (2006). GeoCollaborative crisis management: Designing technologies to meet real-world needs. Proceedings of the 2006 international conference on Digital government research (pp. 71-72). DOI $10.1145 / 1146598.1146624$

Martin, W. J. (2017). The global information society. London, UK: Routledge.

Mastroeni, L., Mazzoccoli, A., \& Naldi, M. (2019). Service level agreement violations in cloud storage: insurance and compensation sustainability. Future Internet, 11(7), 142. DOI 10.3390/fi11070142 
Moore, G. C., \& Benbasat, I. (1991). Development of an instrument to measure the perceptions of adopting an information technology innovation. Information Systems Research, 2(3) 192-222. DOI 10.1287/isre.2.3.192.

Pan, S. L., Pan, G., \& Leidner, D. (2012). Crisis response information networks. Journal of the Association for Information Systems, 13(1), 31. DOI 10.17705/1jais.00283

Powley, E. H. (2009). Reclaiming resilience and safety: Resilience activation in the critical period of crisis. Human relations, 62(9), 1289-1326. DOI 10.1177/0018726709334881

Reuter, C., Marx, A., \& Pipek, V. (2012). Crisis management 2.0: Towards a systematization of social software use in crisis situations. International Journal of Information Systems for Crisis Response and Management (IJISCRAM), 4(1), 1-16. DOI 10.4018/jiscrm.2012010101

Saunders, C. S., \& Jones, J.W. (1992). Measuring performance of the information systems function. Journal of Management Information Systems, 8(4), 63-82. DOI 10.1080/07421222.1992.11517939.

Seeger, M. W., Sellnow, T.L., \& Ulmer, R.R. (2003). Communication and organizational crisis. Greenwood Publishing Group.

Simons, J. (2017). IBM, a pioneer of remote work, calls workers back to the office. The Wall Street Journal [online]. Retrieved from https://www.wsj.com/articles/ibm-a-pioneer-of-remote-workcalls-workers-back-to-the-office-1495108802

Thompson, B. Y. (2019). The digital nomad lifestyle: (remote) work/leisure balance, privilege, and constructed community. International Journal of the Sociology of Leisure, 2(1-2), 27-42. DOI 10.1007/s41978-018-00030-y

Tomaél, M. I. (2000). Fontes de informação na Internet: acesso e avaliação das disponíveis nos sites de universidades. Seminário Nacional de Bibliotecas Universitárias, Florianópolis, Vol. 6.

Turoff, M., Chumer, M., de Walle, B. V., \& Yao, X. (2004). The design of a dynamic emergency response management information system (DERMIS). Journal of Information Technology Theory and Application (JITTA), 5(4), 1-36.

Tworek, K. (2018a). Information systems reliability in the context of higher education institutions. In L. Gómez Chova, A. López Martínez, \& I. Candel Torres (Eds.). Proceedings of the 10th International Conference on Education and New Learning Technologies (pp. 9419-9428). IATED Academy.

Tworek, K. (2018b). Reliability of information systems in organization in the context of banking sector: Empirical study from Poland. Cogent Business \& Management, 5(1). DOI 10.1080/23311975.2018.1522752

Tworek, K. (2019). Aligning IT with business. Cham: Springer.

Tworek, K. (2020). The reliability of Information Systems in organization as a source of competitive advantage. European Journal of International Management, 1(1). DOI 10.1504/EJIM.2020.10018551

Van der Heijden, H. (2004). User acceptance of hedonic information systems. MIS Quarterly, 28(4), 695704. DOI 10.2307/25148660.

Venkatesh, V., Morris, M. G., Davis, G. B., \& Davis, F. D. (2003). User acceptance of information technology: Toward a unified view. MIS Quarterly, 27(3), 425-478. DOI 10.2307/30036540

Watkins, M. (2020). Your crisis response plan: The ten effective elements [online]. Retrieved from https://hbswk.hbs.edu/item/your-crisis-response-plan-the-ten-effective-elements 
Wu, L., \& Buyya, R. (2012). Service level agreement (SLA) in utility computing systems [online]. Retrieved from https://arxiv.org/pdf/1010.2881.pdf

Yeh, Y.-V., \& Lin, C. F. (2015). Aptitude-treatment interactions during creativity training in e-learning: How meaning-making, self-regulation, and knowledge management influence creativity. Educational Technology \& Society, 18(1), 119-131.

Zahedi, F. (1987). Reliability of information systems based on the critical success factors-formulation. Mis Quarterly, pp. 187-203.

The article has been reviewed. | Received: June 27, 2020; Revised: August 1, 2020; Accepted:

August 10, 2020; Pre-published online: November 11, 2020; Published: March 19, 2021. 